\title{
Retrospective cohort study on preparation regimens for frozen embryo transfer
}

\author{
Monique Atkinson, Jenny Crittenden, Howard Smith and Cecilia Sjoblom \\ Westmead Fertility Centre, Westmead Reproduction and Perinatal Centre, Faculty of Medicine and Health, University of Sydney, Westmead Hospital, \\ Corner of Hawkesbury and Darcy Roads, Westmead, New South Wales, Australia
}

Correspondence should be addressed to M Atkinson: monique.atkinson@sydney.edu.au

\begin{abstract}
The objective of this study was to examine the pregnancy outcomes from frozen embryo transfer (FET) cycles using different endometrial preparation regimens, compared to ovulation induction with letrozole (letrozole OI). A retrospective cohort study was conducted at a fertility centre in Sydney, Australia, on 6060 FET cycles. The cycles were stratified into one of four ways to achieve endometrial preparation. These were either a natural, letrozole OI, Ol with follicle-stimulating hormone (FSH OI) or a programmed cycle. The primary outcome was live birth rate (LBR) per embryo transfer. Secondary outcomes included clinical pregnancy and biochemical pregnancy rates, adverse events including miscarriage, ectopic pregnancy, stillbirth, neonatal death and multiple births. Ovarian stimulation parameters were also analysed including the time taken to reach the luteal phase and the number of blood or urine tests required for monitoring the cycle. The results of the study showed that the LBR following letrozole OI cycles was higher when compared to natural cycles (odds ratio (OR): 1.27 (1.07-1.49)) and programmed cycles (OR: 2.36 (1.67-3.34)). There was no significant difference between letrozole OI and FSH OI LBR (OR: 0.99 (0.76-1.28)). An improved LBR with letrozole Ol compared to natural cycles was maintained when only women with a normal length cycle were considered (OR: 1.44 (1.10-1.89)). There was a significant reduction in miscarriage rates when letrozole OI was compared to programmed cycles (OR: $0.46(0.26-0.83)$ ). It was therefore concluded that the use of letrozole OI for endometrial preparation in an FET cycle may be associated with higher LBR and lower miscarriage rate, compared to using a programmed cycle.
\end{abstract}

\section{Lay summary}

Couples suffering from infertility frequently try to conceive following the transfer of an embryo which has been frozen during an in vitro fertilisation cycle. Embryos will only lead to a pregnancy if the woman's womb lining has particular characteristics that allow it to accept the embryo. Despite the thousands of frozen embryo transfer cycles carried out across the world, it is not known how best to prepare a woman's lining so it has these particular characteristics. This study looked at the pregnancy outcomes of 6060 cycles to compare four different ways to prepare a woman's womb lining. These included relying on a woman's natural menstrual cycle, or using an oral medication called letrozole, or injectable medicine called follicle-stimulating hormone, or oestrogen and progesterone hormonal medications. The comparison found that using letrozole before transfer of a frozen embryo may be associated with higher rates of a live birth for some women.

Key Words: letrozole $\quad$ frozen embryo transfer $\quad$ endometrial preparation $\quad$ live birth rate 


\section{Introduction}

Optimal preparation of the endometrium and its synchronisation with the embryo to be transferred is imperative to assure the success of frozen embryo transfers (FETs). There is a paucity of well-designed studies which aim to answer the question of which approach to endometrial preparation achieves the best pregnancy outcomes following FET (Groenewoud et al. 2013, Ghobara et al. 2017, Glujovsky et al. 2020). Common regimens include using a natural cycle with or without human chorionic gonadotrophin (hCG) trigger or a programmed cycle using hormone therapy with or without gonadotrophinreleasing hormone (GnRH) agonist suppression (Ghobara et al. 2017). Alternatively, follicle stimulating hormone (FSH) may be used to induce ovulation. Letrozole is an aromatase inhibitor which has been used for ovulation induction since the early 2000s (Casper \& Mitwally 2011). Its use however for endometrial preparation in FET cycles is less well described yet has shown promising results (Table 1).

Histological and molecular studies have demonstrated that different types of controlled ovarian stimulation can affect the timing and quality of endometrial preparation (Simon et al. 1995, Wu et al. 2020). Hence, the type of endometrial preparation that is used and its resulting hormonal profile has the potential to affect the success rates of embryo transfer.

Letrozole acts by preventing the conversion of androgens to oestrogens in ovarian follicles, peripheral tissues and the brain. This results in a lower level of circulating oestrogens and a higher level of intra-ovarian androgens. The lower oestrogen level releases the hypothalamic-pituitary axis from negative feedback such

Table 1 Studies published regarding using letrozole Ol for endometrial preparation prior to FET. The complete citations are listed in the references list. The study published by Li et al. in 2014 is represented in two parts (part A and part B) as there were two study designs embedded in one publication.

\begin{tabular}{|c|c|c|c|c|c|c|}
\hline \multirow[b]{2}{*}{ Reference } & \multicolumn{3}{|c|}{ Study protocol } & \multirow{2}{*}{$\begin{array}{l}\text { Regimens compared } \\
\text { to letrozole } \\
\end{array}$} & \multirow[b]{2}{*}{ Significant results } & \multirow[b]{2}{*}{ Live birth rate } \\
\hline & Design & Subjects, $n$ & Description & & & \\
\hline $\begin{array}{l}\text { Hosseini-Najarkolaei } \\
\text { et al. (2020) }\end{array}$ & $\mathrm{RCT}$ & 120 & Women with PCOS & Programmed & $\begin{array}{l}\text { No significant } \\
\text { difference }\end{array}$ & Not reported \\
\hline Samsami et al. (2019) & $\mathrm{RCT}$ & 162 & $\begin{array}{l}\text { Women with } \\
\text { regular cycles }\end{array}$ & Programmed & $\begin{array}{l}\text { No significant } \\
\text { difference }\end{array}$ & Not reported \\
\hline Zhang et al. (2019) & $\mathrm{RC}$ & 2664 & Women with PCOS & Programmed & $\begin{array}{l}\text { Less miscarriages with } \\
\text { letrozole }\end{array}$ & $\begin{array}{l}\text { Improved with } \\
\text { letrozole (once } \\
\text { adjusted for } \\
\text { confounding } \\
\text { factors) }\end{array}$ \\
\hline Tatsumi et al. (2017) & $\mathrm{RC}$ & $\begin{array}{c}110,722 \\
\text { cycles }\end{array}$ & & $\begin{array}{l}\text { Natural } \\
\text { Programmed }\end{array}$ & $\begin{array}{l}\text { Improved pregnancy } \\
\text { outcomes with } \\
\text { letrozole: CP, CP with } \\
\text { FHB, MC }\end{array}$ & $\begin{array}{l}\text { Improved with } \\
\text { letrozole }\end{array}$ \\
\hline Aleyasin et al. (2017) & $\mathrm{RCT}$ & 100 cycles & & $\begin{array}{l}\text { Programmed } \\
\text { following } \mathrm{GnRH} \\
\text { agonist } \\
\text { downregulation }\end{array}$ & $\begin{array}{l}\text { Worse implantation } \\
\text { rate with letrozole }\end{array}$ & $\begin{array}{l}\text { No significant } \\
\text { difference }\end{array}$ \\
\hline Sibai et al. (2016) & $\mathrm{RC}$ & 197 cycles & & Programmed & $\begin{array}{l}\text { Improved OPR with } \\
\text { letrozole }\end{array}$ & Not reported \\
\hline Li et al. (2014) & RCT & 713 & $\begin{array}{l}\text { Women with } \\
\text { ovulation disorders }\end{array}$ & Programmed & $\begin{array}{l}\text { Improved pregnancy } \\
\text { outcomes with } \\
\text { letrozole: Implantation } \\
\text { rate, CP, MC }\end{array}$ & $\begin{array}{l}\text { Improved with } \\
\text { letrozole }\end{array}$ \\
\hline Li et al. (2014) & PC & 876 & $\begin{array}{l}\text { Normo-ovulatory } \\
\text { women }\end{array}$ & Natural cycle & $\begin{array}{l}\text { No significant } \\
\text { difference }\end{array}$ & $\begin{array}{l}\text { No significant } \\
\text { difference }\end{array}$ \\
\hline Hu et al. (2014) & $\mathrm{RC}$ & 120 & Women with PCOS & $\begin{array}{l}\text { Programmed, hMG } \\
\text { stimulation }\end{array}$ & $\begin{array}{l}\text { Improved pregnancy } \\
\text { outcomes with } \\
\text { letrozole: CP, OPR }\end{array}$ & Not reported \\
\hline Patel et al. (2011) & $\mathrm{RC}$ & 17 & $\begin{array}{l}\text { Women with } \\
\text { endometriosis }\end{array}$ & $\begin{array}{l}\text { 'Standard hormone } \\
\text { replacement' }\end{array}$ & $\begin{array}{l}\text { Improved CPR with } \\
\text { letrozole: CPR }\end{array}$ & Not reported \\
\hline & & 105 & $\begin{array}{l}\text { Women without } \\
\text { endometriosis }\end{array}$ & & & \\
\hline
\end{tabular}

$\mathrm{CP}$, clinical pregnancy; $\mathrm{CP}$ with $\mathrm{FHB}$, clinical pregnancy with fetal heart beat; OPR, ongoing pregnancy rate; $\mathrm{MC}$, miscarriage; LBR, live birth rate; RCT, randomised controlled trial; $\mathrm{RC}$, retrospective cohort; $\mathrm{PC}$, prospective cohort; $\mathrm{PCOS}$, polycystic ovarian syndrome.

https://raf.bioscientifica.com

https://doi.org/10.1530/RAF-21-0044 (c) 2021 The authors Published by Bioscientifica Ltd

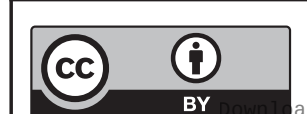

This work is licensed under a Creative Commons Attribution 4.0 International License. 
that a surge in FSH occurs. The FSH surge leads to monofollicular growth and ovulation.

A recent Cochrane review on endometrial preparation in FET cycles concluded that it was uncertain if letrozole OI improved the live birth rate (LBR) (Glujovsky et al. 2020). The review included one randomised controlled trial (RCT) only, comparing LBR in letrozole OI cycles to programmed cycles (Aleyasin et al. 2017). Other RCTs not included in the Cochrane review have reported conflicting outcomes. $\mathrm{Li}$ and co-workers demonstrated a significantly improved LBR with letrozole OI compared to programmed cycles (Li et al. 2014). More recently published RCTs in women with regular cycles (Samsami et al. 2019) or in women with polycystic ovarian syndrome (Hosseini-Najarkolaei et al. 2020), however, did not identify any significant difference in pregnancy outcomes when comparing letrozole OI to programmed cycles (Table 1 ).

To date, there have also been a number of retrospective and prospective cohort studies examining letrozole as an agent for endometrial preparation prior to FET. In general, there has been a consensus that the use of letrozole OI leads to improved FET cycle outcomes (Patel et al. 2011, Hu et al. 2014, Li et al. 2014, Sibai et al. 2016, Tatsumi et al. 2017, Zhang et al. 2019) (Table 1).

The current study aimed to describe the pregnancy outcomes and ovarian stimulation parameters of using letrozole OI as a means of endometrial preparation by retrospectively analysing the cohort data at our institution. It further aimed to examine some of the parameters of the cycles, including the time required to reach the commencement of the luteal phase, in order to guide the selection of women who are appropriate to proceed to embryo transfer.

\section{Materials and methods}

\section{Study design and population}

Women undergoing FET between 2013 and 2018 at Westmead Fertility Centre, Sydney, Australia, were included in this retrospective cohort study. Data were collected and analysed regarding women's demographics, aetiology for infertility, treatment cycle details and pregnancy outcomes.

Pregnancy outcomes were defined as per the European Society on Human Reproduction and Embryology (ESHRE) glossary consensus (Zegers-Hochschild et al. 2017).

Ethical approval for the study was obtained from Western Sydney Local Health District Human Research Ethics Committee (QA 5589).

\section{Frozen embryo transfer cycle regimens}

The regularity of a woman's natural cycle guided the choice of protocol used to prepare women's endometrium prior to FET. The natural cycle was used in women with regular cycles, while letrozole was prescribed to women with irregular or lengthy cycles. FSH OI was used in women who did not respond to the letrozole approach in the previous cycle. Programmed cycles were used in amenorrheic or peri/postmenopausal women. The choice of protocol for some women differed from these general principles as ultimately the choice of protocol used was left up to the treating clinician.

\section{Letrozole OI and natural cycle protocols}

If prescribed letrozole, women took either 2.5 or $5 \mathrm{mg}$ letrozole daily on day 2-6 of their cycle, and tracking was commenced from day 9 to 10 . In a natural cycle, tracking began 16 days prior to their expected next menstrual period based on their previously observed cycle length. Tracking was performed by monitoring oestradiol (E2), luteinising hormone (LH) and progesterone (P4). Once E2 levels were sufficient ( $>400 \mathrm{pmol} / \mathrm{L}$ ), the $\mathrm{LH}$ peak was identified using urinary samples.

\section{FSH OI protocol}

Women commenced FSH (Gonal-F, Merck, Australia or Puregon, Merck Sharp \& Dohme (MSD), Australia) on day 2-3 of their cycle at a dose decided by the treating clinician, most commonly 50-100 IU, guided by markers of the ovarian reserve. Tracking started on day 5-7 of stimulation and was performed with serum hormone and ultrasound analysis. An hCG trigger (Ovidrel $250 \mu \mathrm{g}$, Merck) was administered on confirmation of one or two follicles at $>17 \mathrm{~mm}$ and endometrial thickness $>6 \mathrm{~mm}$. Luteal support was achieved by progesterone pessaries (Oripro, Perrigo, Australia) $200 \mathrm{mg}$ twice daily initiated on the day of embryo transfer.

\section{Programmed protocol}

Oral oestradiol valerate (Progynova, Bayer, Australia) was taken in a step-up approach, from $2 \mathrm{mg}$ daily up to $2 \mathrm{mg}$ three times daily over a 12 - to 14 -day period. Once endometrial thickness was at least $6 \mathrm{~mm}$ on ultrasound assessment, progesterone pessaries $200 \mathrm{mg}$ twice daily were commenced. Luteal phase support was provided by continuing the oestradiol and progesterone until the early pregnancy ultrasound at 7 weeks gestation.

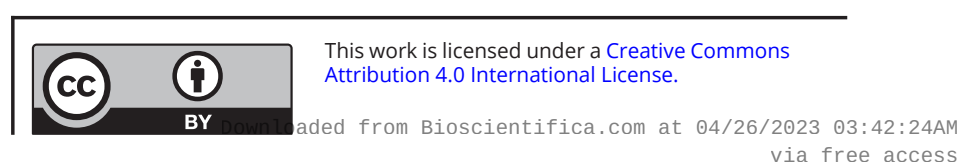




\section{Frozen embryo transfer}

Embryo transfer was performed 2-5 days after the LH peak/ hCG trigger/initiation of vaginal progesterone, depending on the developmental stage at which the embryo had been frozen. Single embryo transfer was encouraged, and a maximum of two embryos could be transferred simultaneously. An embryo was determined to be of good quality if it was graded A or B by the Gardner system at the appropriate stage for its developmental day (Gardner \& Schoolcraft 1999).

\section{Fresh cycle details}

Women underwent controlled ovarian hyperstimulation $(\mathrm{COH})$ using either a GnRH antagonist (Orgalutran, MSD, NJ, USA, or Cetrotide, Merck, Darmstadt, Germany) or agonist protocol (Synarel, Pfizer, West Ryde, Sydney, Australia, or Lucrin AbbVie Pty Ltd, Mascot, Sydney, Australia) together with FSH (Gonal-F, Merck or Puregon, MSD) at a dose selected based on the patient's age, ovarian reserve and any previous response to $\mathrm{COH}$. Follicular development was monitored by serum E2 levels and vaginal ultrasound, with FSH dose adjusted accordingly based on individual patient's ovarian response. Final oocyte maturation was triggered by hCG injection (Ovidrel $250 \mu \mathrm{g}$ ) or GnRH agonist (Lucrin $200 \mu \mathrm{g}$ ) administered when three or more follicles measured $\geq 17 \mathrm{~mm}$. Oocytes were retrieved transvaginally $36-38 \mathrm{~h}$ later. Cumulus-oocyte complexes were inseminated or microinjected approximately 39-40 h after the trigger injection. Fertilisation was assessed 16-18 h postinsemination/injection. Embryos were cultured using the G-series sequential medium (Vitrolife AB, Vasta Frolunda, Sweden). Embryos were assessed as described elsewhere (Alpha Scientists in Reproductive \& Embryology 2011). Fertilised oocytes and cleavage stage embryos were frozen/thawed using the FreezeKit/ThawKit Cleave (Vitrolife $\mathrm{AB}$ ), and blastocysts were vitrified/warmed using RapidVit/ RapidWarm Blast (Vitrolife AB) in accordance with the manufacturer's instructions. Thirty minutes prior to FET, the embryos were placed in EmbryoGlue (Vitrolife AB).

Statistical analysis was performed with the assistance of Christopher Backstrom (Statistiska Konsultgruppen). Baseline characteristics (Table 2) were regarded as independent observations. For comparisons between groups with non-ordered categorical variables, the chisquare test was used, and for continuous variables, the Kruskal-Wallis test was used. Univariable odds ratios (OR) for live birth and miscarriage rates relative to letrozole were calculated by a logistic regression model allowing for repeated measures with compound symmetry covariance structure. The ORs were also adjusted for by age at oocyte pick-up (OPU), embryo quality and stratified by natural cycle length.

\section{Results}

Over the 5-year study period, there were 6072 FET cycles conducted. Of these, 6060 were included for analysis.

Table 2 Clinical baseline characteristics and embryological data of women undergoing FET. For continuous variables, the mean (s.D.) is shown. For binary variables, the number (proportion) of women is shown. Statistical tests identified that there was a significant difference between the groups for all variables $(P<0.05)$.

\begin{tabular}{lcc}
\hline Characteristics & Letrozole \\
\hline$n$ & 830 \\
Age at OPU (years) & $32.6(4.4)$ \\
Age at FET (years) & $34.1(4.3)$ \\
Oocyte or embryo recipient & $16(1.9)$ \\
Aetiology of infertility & \\
$\quad$ Male factor & $237(29.6)$ \\
$\quad$ Endometriosis & $113(13.6)$ \\
$\quad$ Bilateral tubal occlusion & $39(5.7)$ \\
$\quad$ Idiopathic & $140(17.2)$ \\
Natural cycle type & $64(8.1)$ \\
$\quad$ Short (<28 days) & $276(34.7)$ \\
28-35 days & $455(57.2)$ \\
$\quad$ Long (>35 days) & $77(9.3)$ \\
Day of embryo transfer & $753(90.7)$ \\
$\quad$ Cleavage (day 2 or 3) & $668(80.5)$ \\
Day 5 & $724(87.2)$ \\
Good quality embryo transferred & \\
Single embryo transfer & \\
\hline & \\
\hline https://raf.bioscientifica.com & \\
https://doi.org/10.1530/RAF-21-0044 & \\
& \\
\hline
\end{tabular}

\begin{tabular}{c}
\hline Natural \\
\hline 4565 \\
$34.2(4.8)$ \\
$35.6(4.8)$ \\
$53(1.2)$ \\
$1745(38.8)$ \\
$925(20.3)$ \\
$387(9.8)$ \\
$1340(29.8)$ \\
$1156(25.7)$ \\
$2986(66.4)$ \\
$356(7.9)$ \\
$658(14.4)$ \\
$3907(85.6)$ \\
$3629(79.5)$ \\
$3883(85.1)$ \\
\hline CC \\
\hline
\end{tabular}

\begin{tabular}{ccc} 
FSH OI & Programmed \\
\hline $31.8(4.4)$ & & $35.4(6.1)$ \\
$33.5(4.5)$ & & $37.5(6.3)$ \\
$3(0.8)$ & & $116(41.0)$ \\
& & \\
$109(29.4)$ & & $57(20.6)$ \\
$67(17.5)$ & & $51(18.0)$ \\
$20(6.1)$ & & $24(9.5)$ \\
$46(12.2)$ & & $17(6.0)$
\end{tabular}

$15(7.2)$

$64(30.6) \quad 27(14.7)$

$130(62.2) \quad 142(77.2)$

$38(9.9) \quad 108(38.2)$

$344(90.1) \quad 175(61.8)$

$322(84.3) \quad 206(72.8)$

$312(81.7) \quad 221(78.1)$ 
Table 3 Pregnancy outcomes of FET cycles. The cases counted were defined in line with the ESHRE consensus (ZegersHochschild et al. 2017). The table indicates the number (percentage rate) of each variable. The live birth delivery rate represents the number of deliveries that resulted in at least one live birth. Spontaneous miscarriage includes cycles which ended in a spontaneous miscarriage or missed miscarriage.

\begin{tabular}{|c|c|}
\hline & Letrozole \\
\hline Embryo transfers, $n$ & 830 \\
\hline Live birth deliverya & $266(32.0)$ \\
\hline Clinical pregnancya & $336(40.5)$ \\
\hline Biochemical pregnancyb & $50(13.0)$ \\
\hline Spontaneous miscarriage ${ }^{c}$ & $59(17.6)$ \\
\hline Ectopic pregnancyb & $4(1.0)$ \\
\hline Stillbirthd & $3(1.1)$ \\
\hline Neonatal deathe & $1(0.4)$ \\
\hline Multiple delivery (from SET)e & $11(4.6)$ \\
\hline Multiple delivery (from DET) & $6(22.2)$ \\
\hline
\end{tabular}

\begin{tabular}{c}
\hline Natural cycle \\
\hline 4565 \\
$1253(27.4)^{\star}$ \\
$1571(34.4)$ \\
$203(11.4)$ \\
$280(17.8)$ \\
$14(0.8)$ \\
$12(0.9)$ \\
$1(0.1)$ \\
$38(3.4)$ \\
$35(24.3)$ \\
\hline
\end{tabular}

\begin{tabular}{c}
\hline FSH OI \\
\hline 382 \\
$124(32.5)$ \\
$158(41.4)$ \\
$24(13.2)$ \\
$28(17.7)$ \\
$4(2.2)$ \\
$0(0.00)$ \\
$0(0.00)$ \\
$4(4.0)$ \\
$8(32.0)$
\end{tabular}

\begin{tabular}{c}
\hline Programmed \\
\hline 283 \\
$47(16.6)^{*}$ \\
$70(24.7)$ \\
$27(27.6)$ \\
$22(31.4)^{*}$ \\
$1(1.0)$ \\
$0(0.00)$ \\
$0(0.00)$ \\
$0(0.00)$ \\
$4(36.4)$
\end{tabular}

The denominator for the percentage rates calculated was aper embryo transfer cycle, bper pregnancy demonstrated by a positive hCG, cper clinical pregnancy, dper birth, eper live birth delivery from single embryo transfer (SET) or double embryo transfer (DET). *Statistical significance between letrozole and the other regimens for live birth delivery, biochemical pregnancy and spontaneous miscarriage rate was assessed using the chi-square test with significance defined as $P<0.05$.

Twelve cycles were excluded due to missing cycle or pregnancy outcome data.

The majority of women $(4565,75.3 \%)$ had undergone a natural cycle, while 830 (13.7\%) had proceeded with a letrozole OI cycle. The baseline characteristics of women undergoing each cycle type are shown in Table 2. The women undergoing a programmed cycle had an oocyte collection at an older age (35.4 years) compared to other cycles (mean: 31.8-34.2 years). They were also more likely to be an oocyte or embryo recipient (41\% vs $0.8-1.9 \%)$. Of the cycles for which data were available, women having a natural regimen were more likely to have a regular cycle, while women undergoing a letrozole OI regimen were more likely to have a longer cycle.

Cleavage stage embryo transfers were more common in women having a programmed cycle (38.2\%) compared to the other cycles (9.3-14.4\%). There was little difference however between the quality of embryos transferred with $72.8-84.3 \%$ of embryos transferred being graded as good quality. Two embryos were more likely to be transferred in a programmed cycle (21.9\%) compared to other cycles (12.8-18.3\%).

The pregnancy outcomes of the FET cycles are shown in Table 3. The LBR resulting from letrozole OI cycles was significantly higher compared to natural (OR: 1.27 (1.071.49)) or programmed cycles (OR: 2.36 (1.67-3.34)). There was no significant difference between the effect of letrozole compared to FSH OI cycles (OR: 0.99 (0.76-1.28) (Table 4). When adjusted for age and embryo quality, the significant differences were only maintained for letrozole OI above programmed cycles (OR: 1.92 (1.33-2.77)) (Table 4).

The LBR was also examined according to the woman's recorded cycle length (Table 5). A significantly higher LBR was identified in women with a normal cycle length following letrozole OI compared to natural (OR: 1.44 (1.101.89)) or programmed (OR: $4.56(1.45-14.34)$ ) cycles. There was no significant difference in LBR between letrozole OI and the other regimens for women with a short cycle less

Table 4 Pregnancy outcomes from FET cycles, compared to letrozole OI - univariable analysis and adjusted for age at the time of OPU and embryo quality. The odds ratio $(95 \% \mathrm{Cl})$ of the LBR and spontaneous miscarriage rate for each cycle regimen, compared to letrozole OI FETx cycles is shown.

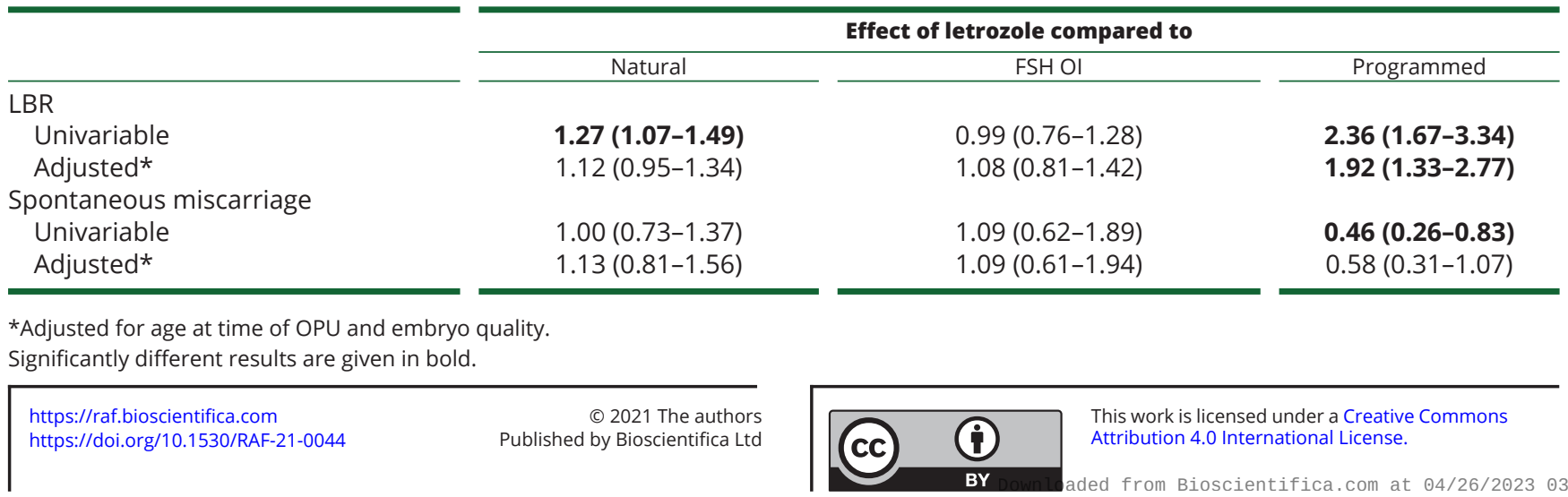


Table 5 Odds ratio for LBR from FET cycles stratified by cycle length, compared to letrozole OI. The table indicates the odds ratio $(95 \% \mathrm{Cl})$ for LBR for each FET cycle type, stratified by cycle length, compared to letrozole OI FETx cycles.

\begin{tabular}{|c|c|c|c|}
\hline & \multicolumn{3}{|c|}{ Effect of letrozole, compared to } \\
\hline & Natural & $\mathrm{FSHOI}$ & Programmed \\
\hline Short (<28 days) & $0.95(0.52-1.74)$ & $0.85(0.26-2.85)$ & $2.10(0.43-10.38)$ \\
\hline 28-35 days & $1.44(1.10-1.89)$ & $1.69(0.89-3.21)$ & $4.56(1.45-14.35)$ \\
\hline Long (>35 days) & $1.09(0.80-1.47)$ & $0.83(0.56-1.24)$ & $2.29(1.41-3.71)$ \\
\hline
\end{tabular}

Significantly different results are given in bold.

than 28 days. For those women with a cycle longer than 35 days, letrozole OI was only beneficial when compared to programmed cycles (OR: 2.02 (1.24-3.29)).

The rate of spontaneous miscarriage only differed from letrozole OI cycles when programmed cycles were used (OR: 0.46 (0.26-0.83)) (Table 4). This effect however was not maintained when adjusted for age and embryo quality (OR: 0.58 (0.31-1.07)) (Table 4).

The duration of the follicular phase of each cycle type was assessed (Table 6). For those letrozole OI, natural and FSH OI cycles that led to a live birth, the mean duration of the follicular phase was 15-16 days. Programmed cycles had a slightly longer follicular phase of 18 days. FSH OI cycles could adequately prepare the endometrium following only 5 days of stimulation. Other cycle types however needed 8-10 days of a follicular phase if the cycle was to lead to a live birth. Embryo transfers which were performed after a follicular phase of 30-38 days did not result in a live birth (Table 6).

Compared to letrozole OI and natural cycles, the number of blood or urine tests required by women undergoing an FSH OI cycle was at least two times greater (Table 6).

\section{Discussion}

The current study suggests that using letrozole to achieve endometrial preparation prior to FET may yield a higher LBR, compared to natural and programmed cycles (Tables 3 and 4). This however should be interpreted with caution as it may not apply for all women. Further, the outcome data from this retrospective cohort may be confounded by variables which could not be accounted for. The women being chosen for each cycle type are likely to represent groups with variable prognoses. In total, $57.2 \%$ of women having a letrozole OI cycle and $62.2 \%$ having an FSH OI cycle had long cycles (Table 2). This is in contrast to only $7.9 \%$ of women chosen to have a natural cycle. The most common reason for oligomenorrhoea is polycystic ovarian syndrome (PCOS). It is likely that women with PCOS are over-represented in the OI cycles, and as a result, they may have a better prognosis due to their higher ovarian reserve. However, in programmed cycles, where $77.2 \%$ of women were defined as having a long cycle, this may actually represent those women with ovarian insufficiency and hence a poor prognosis. This may be partially counterbalanced by the fact that $41 \%$ of those women were a recipient of donor oocytes or embryos.

The type of regimen to use for women with a normal length cycle is frequently debated. It is proposed that the use of ovulation induction with either letrozole or FSH, even in the presence of spontaneous folliculogenesis and an LH surge, may enhance endometrial preparation. The current study suggests that letrozole OI improved the LBR for women with a regular cycle compared to a natural cycle (OR: 1.44 (1.10-1.89)) (Table 5). It may be that while women seem to demonstrate a normo-ovulatory cycle, the quality of their endometrial preparation, driven by folliculogenesis and corpus luteum formation, may be impaired in a way that we currently lack a diagnostic tool for. The use of letrozole OI may circumvent this defect.

For women with a long cycle, programmed or OI regimens are more commonly employed. The current study demonstrated that letrozole yielded a higher LBR, compared to programmed cycles (OR 2.02 (1.24-3.29)) in this population group (Table 5). In a study of women with PCOS, Zhang et al. demonstrated that after adjusting for age, letrozole OI led to a higher LBR (Zhang et al. 2019). In one of the few RCTs involving letrozole OI for FET, Li et al. demonstrated that in women with ovulatory disorders, a letrozole endometrial preparation regimen led to a higher LBR compared to a programmed cycle (Li et al. 2014).

The inferiority of programmed cycles quite consistently across this current study and previously published literature may be linked to the importance of the corpus luteum in establishing and maintaining a pregnancy. It has recently been highlighted that pregnancies of women who have conceived following FET have demonstrated a higher incidence of hypertensive disorders of pregnancy (Ishihara et al. 2014, Sha et al. 2018). This is thought to be associated with the absence of the corpus luteum and its secretion of hormones such as relaxin and the subsequent placentation events which occur (Ginstrom Ernstad et al. 2019, von Versen-Hoynck et al. 2019, Dall'Agnol \& Garcia Velasco 2020). The pregnancy outcomes demonstrated in the current study further support the important role the corpus luteum plays in the establishment of a pregnancy.

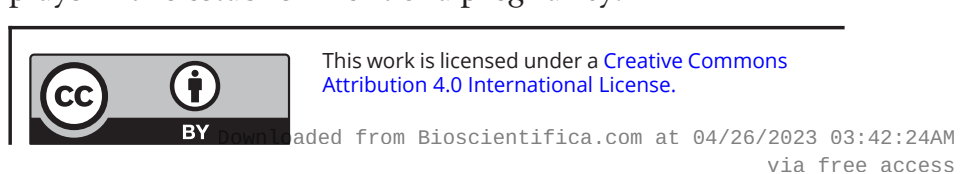


Table 6 Secondary outcomes from FET cycles. The follicular phase was defined as the number of days from a woman's first day of her last menstrual period to her natural LH surge (for letrozole OI, natural cycles), trigger (FSH OI cycles) or commencement of progesterone (programmed cycles).

\begin{tabular}{|c|c|c|c|c|}
\hline & Letrozole & Natural cycle & FSH OI & Programmed \\
\hline \multicolumn{5}{|l|}{$\begin{array}{l}\text { Length of follicular phase to achieve positive bHCG } \\
\text { (days) }\end{array}$} \\
\hline Minimum & 9 & 8 & 5 & 9 \\
\hline \multicolumn{5}{|l|}{$\begin{array}{l}\text { Length of follicular phase to achieve live birth } \\
\text { (days) }\end{array}$} \\
\hline Minimum & 10 & 8 & 5 & 9 \\
\hline 5th percentile & 11 & 11 & 8 & 10.4 \\
\hline Mean & 15.47 & 15.02 & 16.07 & 18.17 \\
\hline 95th percentile & 22 & 21 & 26 & 26.6 \\
\hline Maximum & 30 & 34 & 38 & 28 \\
\hline Blood or urine samples taken during cycle (mean) & 2.6 & 2.1 & 5.5 & 1.0 \\
\hline
\end{tabular}

Statistical tests identified that there was a significant difference $(P<0.05)$ between the groups for all parameters.

The strength of this study is that, to our knowledge, it is the only study published which includes a comparison of the four most commonly used endometrial preparation techniques within one cohort (Table 1). The sample size is extensive compared to previously published literature hence potentially ensuring that the sample of women studied more closely approximates the population of women undergoing FETs.

This study is also unique in that it explored the duration of the follicular phase of a cycle required to lead to a pregnancy resulting in a live birth. This can serve as a guide when assessing hormonal results suggestive of either short or long follicular phase lengths. It suggests, for example, in women having a letrozole OI FET cycle, if a peak oestrogen is reached prior to day 10 , it may be worthwhile cancelling the cycle. The absence of live births prior to this may indicate that there is an inadequate length of time available for appropriate oestrogen levels to act on the endometrium.

At the other end of the spectrum, 95\% of letrozole OI FET live births were achieved if the follicular phase was up to 22 days in duration, while the longest follicular phase at which a live birth was achieved was 30 days. Previous studies exploring the endocrine profiles of ovulatory women taking letrozole have indicated a narrow CI for the follicular phases observed (13.1 \pm 0.3 days) (Jirge \& Patil 2010). The current paper highlights that many women will not fall into this narrow definition of a follicular phase length and so it is worthwhile persisting with the cycle, even in the face of an apparently 'long' follicular phase. In fact, of the 31 women who had a follicular length of 22-30 days in duration with a letrozole OI cycle, 12 achieved a live birth following embryo transfer, giving an LBR of 39\%.
The current study is however limited by its retrospective cohort, non-randomised design. Details of the woman's baseline fertility prognosis and data regarding previous cycles, including fresh cycle details, were not assessed. This makes it challenging to assess if the findings are specific to a particular group of women defined by certain characteristics or if they have been confounded by other factors such as duration or aetiology of infertility or BMI.

In the absence of clear evidence which definitively demonstrates an improved LBR with one particular regimen, other elements of a FET cycle should be considered. These include the cost to the patient or the healthcare system in terms of resources required to track a cycle (time, equipment and personnel) or medicationrelated costs. Around twice as many blood or urine tests were required to manage an FSH OI cycle compared to a natural or letrozole OI cycle (Table 6). Some patients may be particularly averse to using injectable medications and so an oral letrozole regimen may be more suitable. Further, when assessing the burden of treatment, the cost of FSH preparations needs to be considered, which could be up to 20 times that of letrozole.

Noting their different mechanisms of action, it is likely that each endometrial preparation regimen may better suit women defined by particular characteristics. In order to determine this, a prospective study randomising women stratified by their baseline fertility prognosis and diagnosis would be worthwhile. Due to the large number of women required however to achieve sufficient power, an alternative is to continue performing retrospective studies. It is critical however that clinics focus on the accurate collection and regular auditing of uniform data to ensure appropriate big data analyses can be performed. https://raf.bioscientifica.com

https://doi.org/10.1530/RAF-21-0044 (c) 2021 The authors Published by Bioscientifica Ltd

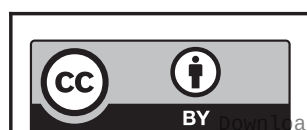

This work is licensed under a Creative Commons Attribution 4.0 International License. 
Any future studies should also examine the longterm pregnancy and neonatal outcomes as the cycle type may influence the occurrence of hypertensive disorders of pregnancy or growth restriction (Dall'Agnol \& Garcia Velasco 2020). The differences in pregnancy outcomes demonstrated in this study also highlight the importance of clearly stating the type of FET cycle performed, when comparing 'fresh' to 'frozen' embryo transfers. It is becoming more clear that not all FET cycles are equivalent.

\section{Conclusion}

This retrospective cohortstudy demonstrated a significantly higher LBR and lower miscarriage rate in women having FET in letrozole OI cycles compared to programmed cycles. The difference in LBR between letrozole OI and FSH OI cycles was not found to be significant, while that between letrozole OI and natural cycles was no longer significant after adjusting for potential confounders. Patients having an FSH OI cycle incurred a higher expense for drugs and had twice as many test occasions compared to letrozole OI patients. This indicates that when considering the cost and burden of treatment, the preferred OI endometrial preparation for FET is letrozole.

Declaration of interest

The authors declare that there is no conflict of interest that could be perceived as prejudicing the impartiality of the research reported.

\section{Funding}

This work did not receive any specific grant from any funding agency in the public, commercial, or not-for-profit sector.

\section{Author contribution statement}

$\mathrm{M} \mathrm{A}$ and C S conceived the study question and designed the type of data to be extracted from the database. J $C$ extracted the data from the clinical database. M A performed the literature review, was responsible for ethics approval application and collated the data for review by the statistician (C B acknowledged below). M A wrote the paper, while C S and H S provided editorial support to draw final conclusions and prepare the article for publication.

\section{Acknowledgement}

The authors thank Christopher Backstrom for statistical support.

\section{References}

Aleyasin A, Aghahosseini M, Safdarian L, Noorzadeh M, Fallahi P, Rezaeian Z \& Hoseinimosa S 2017 Can letrozole plus HMG protocol improve pregnancy outcomes in frozen-thawed embryo transfer? An RCT. International Journal of Reproductive Biomedicine $\mathbf{1 5}$ 83-86. (https://doi.org/10.29252/ijrm.15.2.83)

Alpha Scientists in Reproductive Medicine and ESHRE Special Interest Group of Embryology, ESIGO 2011 The Istanbul consensus workshop on embryo assessment: proceedings of an expert meeting. Human Reproduction 26 1270-1283. (https://doi.org/10.1093/humrep/der037)

Casper RF \& Mitwally MF 2011 Use of the aromatase inhibitor letrozole for ovulation induction in women with polycystic ovarian syndrome. Clinical Obstetrics and Gynecology 54 685-695. (https://doi.org/10.1097/ GRF.0b013e3182353d0f)

Dall'Agnol H \& Garcia Velasco JA 2020 Frozen embryo transfer and preeclampsia: where is the link? Current Opinion in Obstetrics and Gynecology 32 213-218. (https://doi.org/10.1097/ GCO.0000000000000624)

Gardner DK \& Schoolcraft WB (eds) 1999 In Vitro Culture of Human Blastocyst. Carnforth: Parthenon Publishing Group Press.

Ghobara T, Gelbaya TA \& Ayeleke RO 2017 Cycle regimens for frozenthawed embryo transfer. Cochrane Database of Systematic Reviews 7 CD003414. (https://doi.org/10.1002/14651858.CD003414.pub3)

Ginstrom Ernstad E, Wennerholm UB, Khatibi A, Petzold M \& Bergh C 2019 Neonatal and maternal outcome after frozen embryo transfer: increased risks in programmed cycles. American Journal of Obstetrics and Gynecology 221 126.e1-126.e18. (https://doi. org/10.1016/j.ajog.2019.03.010)

Glujovsky D, Pesce R, Sueldo C, Quinteiro Retamar AM, Hart RJ \& Ciapponi A 2020 Endometrial preparation for women undergoing embryo transfer with frozen embryos or embryos derived from donor oocytes. Cochrane Database of Systematic Reviews 10 CD006359. (https://doi.org/10.1002/14651858.CD006359.pub3)

Groenewoud ER, Cantineau AE, Kollen BJ, Macklon NS \& Cohlen BJ 2013 What is the optimal means of preparing the endometrium in frozen-thawed embryo transfer cycles? A systematic review and meta-analysis. Human Reproduction Update 19 458-470. (https://doi.org/10.1093/humupd/dmt030)

Hosseini-Najarkolaei A, Moini A, Kashani L, Farid Mojtahedi M, Hosseini-Najarkolaee E \& Salehi E 2020 The effect of letrozole versus artificial hormonal endometrial preparation on pregnancy outcome after frozen-thawed embryos transfer cycles: a randomized clinical trial. Reproductive Biology and Endocrinology 18 115. (https://doi. org/10.1186/s12958-020-00675-z)

Hu YJ, Chen YZ, Zhu YM \& Huang HF 2014 Letrozole stimulation in endometrial preparation for cryopreserved-thawed embryo transfer in women with polycystic ovarian syndrome: a pilot study. Clinical Endocrinology 80 283-289. (https://doi.org/10.1111/cen.12280)

Ishihara O, Araki R, Kuwahara A, Itakura A, Saito H \& Adamson GD 2014 Impact of frozen-thawed single-blastocyst transfer on maternal and neonatal outcome: an analysis of 277,042 singleembryo transfer cycles from 2008 to 2010 in Japan. Fertility and Sterility 101 128-133. (https://doi.org/10.1016/j.fertnstert.2013.09.025)

Jirge PR \& Patil RS 2010 Comparison of endocrine and ultrasound profiles during ovulation induction with clomiphene citrate and letrozole in ovulatory volunteer women. Fertility and Sterility 93 174-183. (https://doi.org/10.1016/j.fertnstert.2008.10.009)

Li SJ, Zhang YJ, Chai XS, Nie MF, Zhou YY, Chen JL \& Tao GS 2014 Letrozole ovulation induction: an effective option in endometrial preparation for frozen-thawed embryo transfer. Archives of Gynecology and Obstetrics 289 687-693. (https://doi.org/10.1007/s00404-013-3044-0)

Patel BG, Bushnell G, Higdon HL, Miller PB, Forstein DA \& Lessey BA 2011 Letrozole use in frozen embryo transfer (FET) cycles: clinical pregnancy outcomes in patients with and without https://raf.bioscientifica.com

https://doi.org/10.1530/RAF-21-0044 (c) 2021 The authors Published by Bioscientifica Ltd

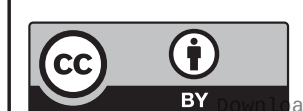

This work is licensed under a Creative Commons Attribution 4.0 International License. 
endometriosis. Fertility and Sterility 96 S276. (https://doi.org/10.1016/j. fertnstert.2011.07.1052)

Samsami A, Ghasmpour L, Davoodi S, Moradi Alamdarloo S, Rahmati J, Karimian A \& Homayoon H 2019 Frozen embryo transfer: endometrial preparation by letrozole versus hormone replacement cycle: a randomized clinical trial. International Journal of Reproductive Biomedicine 17 915-922. (https://doi.org/10.18502/ijrm. v17i12.5793)

Sha T, Yin X, Cheng W \& Massey IY 2018 Pregnancy-related complications and perinatal outcomes resulting from transfer of cryopreserved versus fresh embryos in vitro fertilization: a metaanalysis. Fertility and Sterility 109 330.e9-342.e9. (https://doi. org/10.1016/j.fertnstert.2017.10.019)

Sibai H, Husseiny AA \& Elgindy E 2016 Letrozole versus artificial hormonal endometrial preparation for vitrified-warmed embryos transfer cycles. Middle East Fertility Society Journal 21 96-100. (https:// doi.org/10.1016/j.mefs.2015.09.002)

Simon C, Cano F, Valbuena D, Remohi J \& Pellicer A 1995 Clinical evidence for a detrimental effect on uterine receptivity of high serum oestradiol concentrations in high and normal responder patients. Human Reproduction 10 2432-2437. (https://doi.org/10.1093/ oxfordjournals.humrep.a136313)

Tatsumi T, Jwa SC, Kuwahara A, Irahara M, Kubota T \& Saito H 2017 Pregnancy and neonatal outcomes following letrozole use in frozen-thawed single embryo transfer cycles. Human Reproduction $\mathbf{3 2}$ 1244-1248. (https://doi.org/10.1093/humrep/dex066) von Versen-Hoynck F, Strauch NK, Liu J, Chi YY, Keller-Woods M, Conrad KP \& Baker VL 2019 Effect of mode of conception on maternal serum relaxin, creatinine, and sodium concentrations in an infertile population. Reproductive Sciences 26 412-419. (https://doi. org/10.1177/1933719118776792)

Wu JL, Keller P, Kanchwala M, Xing C, Babayev SN, Carr BR, Bukulmez O \& Word RA 2020 Controlled ovarian stimulation protocols alter endometrial histomorphology and gene expression profiles. Reproductive Sciences 27 895-904. (https://doi.org/10.1007/ s43032-019-00093-6)

Zegers-Hochschild F, Adamson GD, Dyer S, Racowsky C, De Mouzon J, Sokol R, Rienzi L, Sunde A, Schmidt L, Cooke ID, et al. 2017 The international glossary on infertility and fertility care, 2017. Human Reproduction 32 1786-1801. (https://doi.org/10.1093/ humrep/dex234)

Zhang J, Liu H, Wang Y, Mao X, Chen Q, Fan Y, Xiao Y \& Kuang Y 2019 Letrozole use during frozen embryo transfer cycles in women with polycystic ovary syndrome. Fertility and Sterility 112 371-377. (https://doi.org/10.1016/j.fertnstert.2019.04.014)

Received in final form 12 November 2021

Accepted 23 November 2021

Accepted Manuscript published online 23 November 2021 (c) 2021 The authors Published by Bioscientifica Ltd

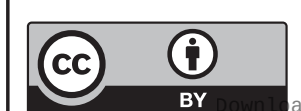

This work is licensed under a Creative Commons Attribution 4.0 International License. 